\title{
Research on Development Expenditure Forecasting of Deepwater Oilfield in Gulf of Mexico
}

\author{
Mingyu Shi ${ }^{1, a,{ }^{*}}$, Chenggao $\mathrm{Yi}^{1, \mathrm{~b}}$, Jianjun Wang ${ }^{1, \mathrm{c}}$, Jianhui Bai ${ }^{1, \mathrm{~d}}$ \\ ${ }^{1}$ Research Institute of Petroleum Exploration \& Development, Beijing, China \\ ashimingyu@petrochina.com.cn, byichenggao@petrochina.com.cn, \\ 'wangjianjun@petrochina.com.cn, dbaijianhui@petrochina.com.cn, \\ ${ }^{*}$ Corresponding author
}

Keywords: Gulf of Mexico; ocean engineering; development cost; investment forecast

Abstract. Gulf of Mexico(GoM) is the earliest deep-water oilfields that have been developed. Especially after the 2010's BP oil leakage accident, more and more efficient, safe and inexpensive development key technology have been put into use in this area. Therefore, researching on this important deep-water area tends to be reference valuable to development of deep-water oilfields all over the world. This paper analysis the developing concept in recent 10 years and the EPC contract price of deep-water ocean engineering construction expenditure in GoM. By running the biggest cost database of software QUE\$TOR and analyzing the cost data of result, the analysis and forecast have been done for the deep-water oil and gas development expenditure in GoM, exploring the relevance between the cost index and oil price.

\section{美国墨西哥湾深海油气田开发海洋工程成本分析及预测研究 \\ 史洺宇 $1, \mathrm{a}^{*}$ ，易成高 ${ }^{1, \mathrm{~b},}$ ，王建君 ${ }^{1, \mathrm{c},}$ ，白建辉 ${ }^{1, \mathrm{~d}}$ \\ 1中国石油勘探开发研究院国际项目评价研究所，北京，中国 \\ ashimingyu@petrochina.com.cn, byichenggao@petrochina.com.cn, \\ cwangjianjun@petrochina.com.cn, dbaijianhui@petrochina.com.cn,}

关键词:墨西哥湾; 海洋工程; 开发成本; 投资预测

中文摘要.墨西哥湾是世上最早开发的海上油气田, 尤其在2010年BP漏油事故后, 该区域更加 成为了孕育更加高效、安全、低廉的深海油气开发关键技术的摇篮。因此，对墨西哥湾区域 的研究对全球重点海域具有相当的参考价值。本文分析近十年美国墨西哥湾实际深海开发海 工模式以及海工承包商造价，比选深海平台的经济性。并使用全球最大成本数据库旗下软件 对油田算例成本进行模拟研究, 对墨西哥湾深海海域油气田开发成本展开分析和预测,探索成 本指标与油价之间的相关性。

\section{1. 墨西哥湾主要海工开发模式与区域承包商造价分析}

通过研究统计美国墨西哥湾近十年签署和新建的浮式平台情况，近十年美国墨西哥湾 90\%以上的深海油气开发采取 “浮式平台+水下生产系统” 的模式（见图1），平台形式主要 包括TLP (张力腿式平台)、SPAR（深水浮筒式平台）、Semi (半潜式平台) 等, 因为美国 墨西哥湾区域的深海浮式平台的建造能力能够满足区域深海开发的需求，其承包商距离市场 较近，运输和安装费用低，致其总体海洋工程投资较经济。

基于不同油气处理规模对美国墨西哥湾近十年新建浮式平台的经济性对比, 采用平台单 位处理规模下的投资额作为评价对比指标，并对该指标统计进行线性拟合（见图2）。对于同 
一时期建造、处理规模相近而不同类型的浮式生产平台，从平台造价来看经济性最优的是半 潜式平台, 其单位产能规模的平台投资额位于 1 万美元/bopd, 其次是深水浮筒式平台, 经济 性最差的是张力腿式平台。也就是说, 所建造的半潜式平台处理能力每增加 1 桶/天, 将要多 花费1万美元的成本。实际上, 2006年至今, 美国墨西哥湾近十年新建浮式生产设施中采用最 多的是半潜式平台。

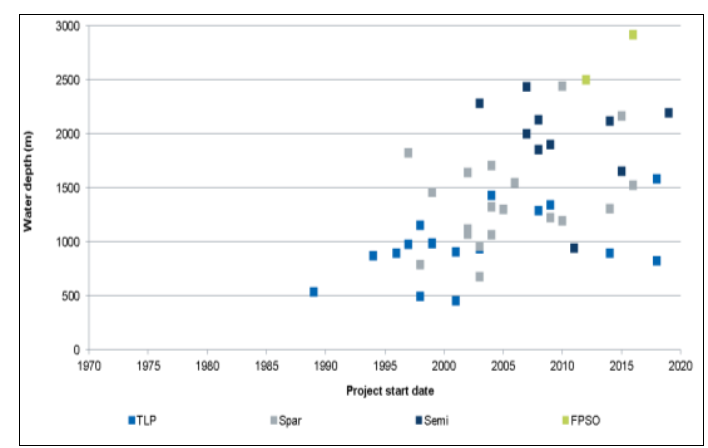

图1 美国墨西哥湾不同水深深海油气开发模式

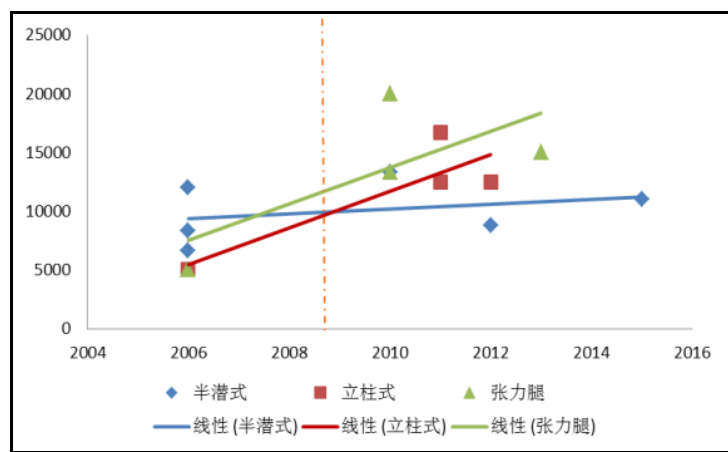

图2 美国墨西哥湾浮式平台单位规模投资（\$USD/bopd）

\section{2. 美国墨西哥湾深海油田算例成本研究}

为了进一步研究论证深海生产平台的经济性, 以美国墨西哥湾深海 $\mathrm{T}$ 油田的开发为案例, 采用QUE\$TOR软件对其海工模式进行规划模拟计算。针对 T油田规划采用 “浮式平台+水下 生产系统+海底外输管道” 的海工模式进行开发, 浮式平台采用TLP (张力腿式平台)、SPAR

（深水浮筒式平台）或Semi（半潜式平台）, 对其三种开发方式进行模拟计算, 对计算结果 中的CAPEX (初始投资) 进行分析。深海油气开发CAPEX（见图3）由深海钻井、海工成本 构成, 其中T区块主要生产参数设置见表 1 。

表 1 美国墨西哥湾深海 $\mathrm{T}$ 区块主要基础参数

\begin{tabular}{|c|c|c|c|c|c|}
\hline 可采储量 & 7000万吨 & 水深 & 1600米 & 注水井 & 6口 \\
\hline 建成规模 & 350万吨/年 & 油藏埋深 & 4000米 & 生产汽油比 & $320 \mathrm{~m}^{3} / \mathrm{m}^{3}$ \\
\hline 开发井 & 20 口 & 油田开发期 & 20年 & 海面平均气温 & $32^{\circ} \mathrm{C}$ \\
\hline 离岸距离 & 120公里 & 原油 $\mathrm{API}^{\circ}$ & 31.6 & 海水平均温度 & $10^{\circ} \mathrm{C}$ \\
\hline
\end{tabular}

海工成本包括平台费用、水下生产系统、海底外输管线等，其中平台费用占据CAPEX的 12-20\%。算例结果表明, TLP平台CAPEX相对较高, 约48.9亿美元; SPAR平台CAPEX约48.2 亿美元; Semi平台CAPEX约42.9亿美元。也就是说采用Semi平台相较采用TLP、SPAR可节约 成本约 $10 \%$ 。从该算例结果分析得出, 美国墨西哥湾深海油气开发选择半潜式平台能够获得 更好的经济性。这一结论同承包商造价分析得出的结论以及近十年美国墨西哥湾的实际平台 的采用情况是一致的。

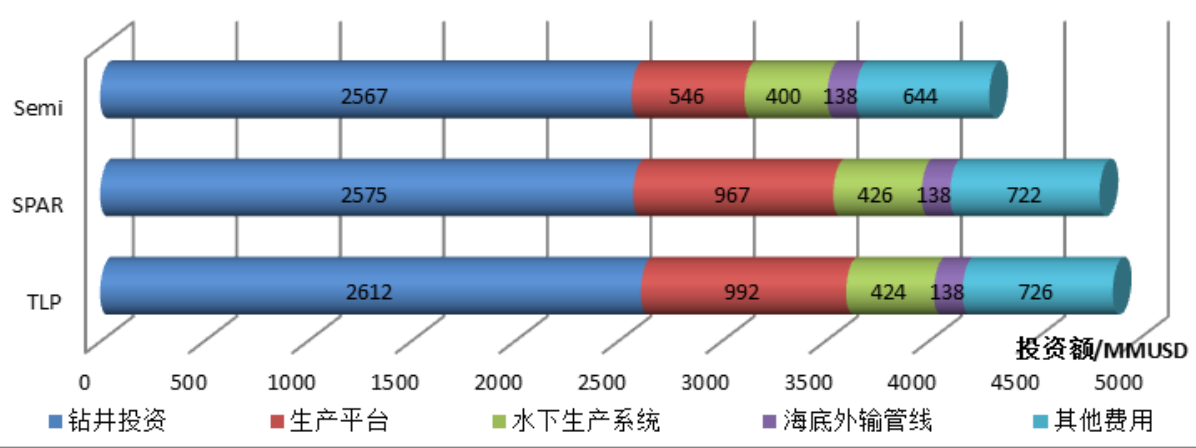

图3 T区块算例-CAPEX分析对比图 


\section{3. 海工成本趋势分析预测}

对区域2000-2016年的上述各项海工成本指数的变化趋势进行分析（见图4）。分析发现， 在2000年-2014年期间, 各项海工成本指数稳步攀升, 在2013-2014年间均达到峰值。随着2015 年油价下跌, 半潜式平台及深水浮筒式平台的成本指数敏感性较强, 其成本指数在过去的 3 年之中分别下跌了 $31 \%$ 和 $39 \%$ 。相比之下, 张力腿式平台及水下生产系统的成本指数分别下 降 $22 \%$ 及 $19 \%$ 。

Semi平台及SPAR平台从2014年至今需求量大幅下降, 因为仅韩国范围内的承包商建造能 力就能够满足全球范围内对这两种平台的整体建造需求。随着油价的回升, 未来Semi和SPAR 海工成本指数年平均上涨 $3.1 \%$; Subsea及TLP海工成本指数年平均上涨 $4.2 \%$, 预计 2022 年前 后将达到2013年成本水平。半潜式平台和SPAR平台未来成本指数增速缓慢, 而水下生产系统 成本指数将稳步上升, 但在短期也难以回到2014年高峰时期的成本水平。由此同样可以看出, 基于目前海工市场及政策条件下, 半潜式生产平台+水下生产系统可以作为深海油气开发的优 先选项。

深海CAPEX及OPEX的变化显现出相对于油价展现出 “滞后” 的变化趋势, OPEX整体趋 势始终维持上涨态势。CAPEX整体趋势显现出 “一波三折” 的态势：2008年前后的 “涨-平” 促使未来3年内投资指标的平稳过渡；2014年前后的 “涨-跌”，油价的暴跌将正当高位的指 标下拉了 $20 \%$; 随着油价的回升, 投资指标也将有所反弹, 在2019年前后恢复至2013年前后 的水平。OPEX受到油价起伏的控制，整体保持上升的趋势。

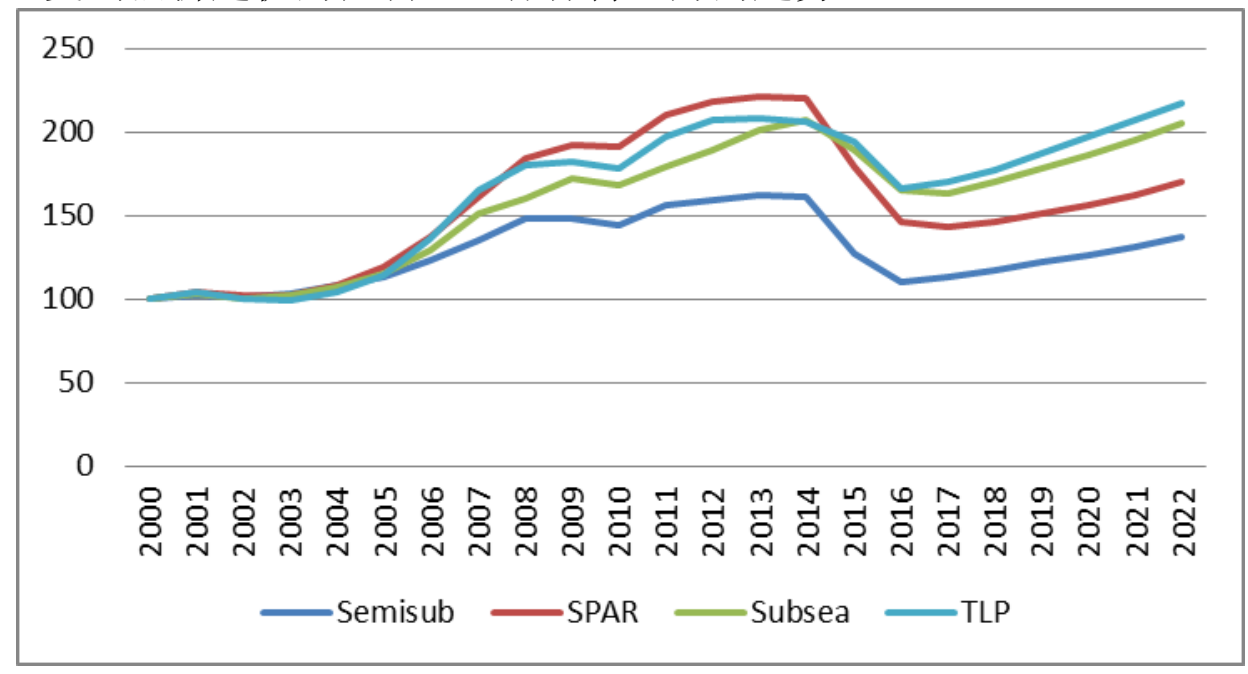

图4 墨西哥湾深海平台成本指数变化趋势及预测

\section{4. 油气开发成本 (CAPEX/OPEX) 分析预测}

综合上述钻井及海工成本的历史趋势展开区域油气开发成本预测, 美国墨西哥湾深海油 气开发CAPEX及OPEX的变化趋势具有一致性, 深海CAPEX及OPEX的变化显现出相对于油 价明显 “滞后” 的变化趋势（图5）。尽管2009年及2014年随着油价的波动开发成本经历了下 滑, 然而从整体来看CAPEX及OPEX始终处于上涨的趋势。据此预测区域深海CAPEX及OPEX 在未来3-5年内可能随着油价的回暖缓步上升, CAPEX在2019年前后将恢复至2013年前后的 水平。 


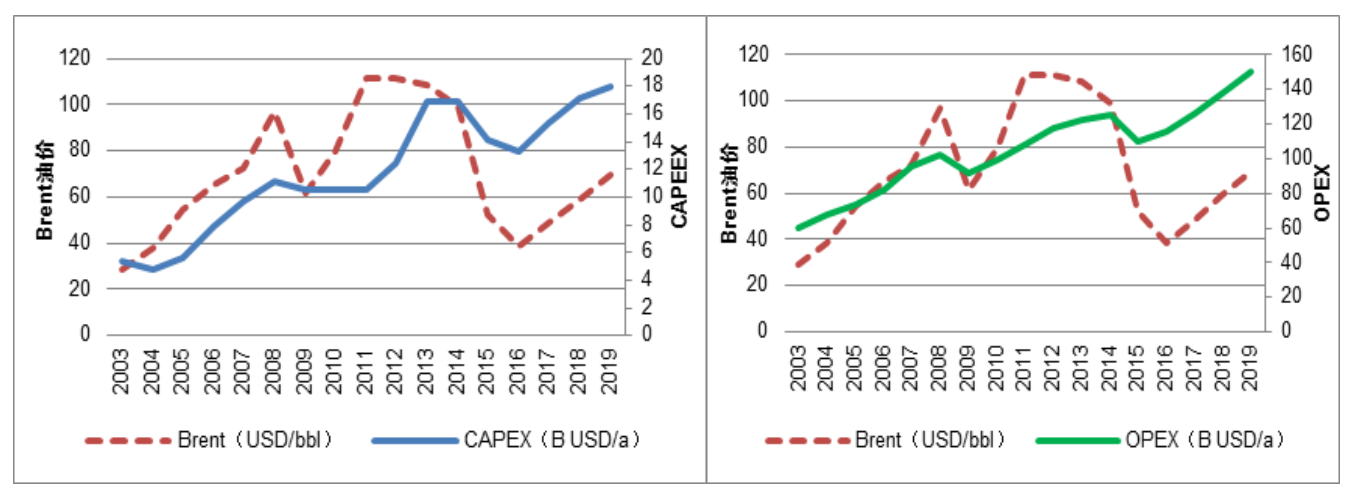

图5 美国墨西哥湾深海开发成本（CAPEX/OPEX）随油价变化趋势及预测

\section{4. 结论}

（1）美国墨西哥湾采用最多的开发模式是 “浮式平台+水下生产系统”。近十年半潜式 平台的使用频率较高。美国墨西哥湾本地承包商具备集成建造浮式平台的能力, 供应商距离 作业区近, 运输成本低, 且针对美国墨西哥湾深海的深水、气候、海况条件, 半潜式平台在 美国墨西哥湾具有一定的经济性和可操作性。

（2）展望未来，采用 “FPSO+水下生产系统”进行油气田的开发利用在美国墨西哥湾的 部分项目将得到更加广泛的应用, 系列概念也将为全球深海油气规模开发利用带来革命性进 步。

（3）深海平台造价和经济性受到多重因素控制。通常油气处理规模越大，单位处理规模 的平台成本指标越高, 因此往往需要高产量、稳产持久的油气田来保证深海油气开发期内的 经济效益最大化。

（4）深海海工投资的变化趋势显现出 “一波三折” 的态势，其相对于油价的变化整体呈 现相对 “滞后” 的变化趋势。

\section{References}

[1] Wei Wang. Four challenges of deep water oil and gas development [J]. Petroleum Knowledge.2015,(6): 5-7

[2] Lichen Wang. Global investment trend exploration and development of oil and gas. [J].International Petroleum Economy.2014,(9): 34-37

[3] Yaxing Liu. The thinking of South China Sea oil and gas exploration and production according to the status of the resource exploration of Gulf of Mexico [J]. China Mining Magazine. 2012,21(9):17-19.

[4] Chenggao Yi. The new technique and tendency of global oil and gas development [A]. 14th National College Academic Communication of Oil and Gas Storage and Transportation. 2016,(7): 1-7.

[5] Wood Mackenzie. Mexico's Round One deepwater exploration: big Gulf of Mexico opportunities[DB/OL]. WoodMackenzie[2016-01-14] : 1-4.

[6] Wood Mackenzie. Deepwater Gulf of Mexico Briefing 2015[DB/OL]. WoodMackenzie [2015-11-04]:1-2.

[7] B.A. Magnell. A Database of Oil Industry Deepwater Current Measurements[A]. Offshore Technology Conference. 2014: OTC-25369-MS. 